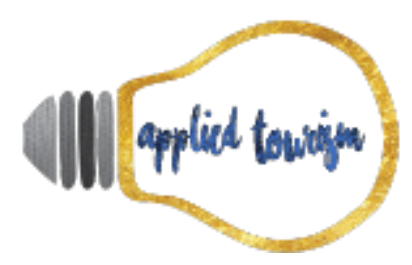

Volume 3, número 2, 2018, p. 36- 57

\title{
ENTRE ENCONTROS E (DES) ENCONTROS: A Sustentabilidade de um Roteiro Turístico na Reserva Indígena de Dourados / MS.
}

\author{
Algemiro de Souza \\ Bacharel em Turismo, Universidade Estadual do Mato Grosso do Sul \\ algemirodourados@gmail.com \\ Fábio Orlando Eichenberg \\ Doutor em Geografia, Universidade Federal da Grande Dourados \\ Docente em Turismo da Universidade Estadual do Mato Grosso do Sul \\ eichenber10@gmail.com
}

Recebido: 11 de setembro, 2017 Aprovado: 19 de outubro, 2017

\section{RESUMO}

O presente artigo teve como objetivo principal discutir a viabilidade técnica, social e econômica, de um roteiro sustentável de turismo em terra indígena nos limites da Reserva Indígena de Dourados. A metodologia utilizada foi a pesquisa bibliográfica e aplicação de questionário aos visitantes, comunidade local, lideranças indígenas e também agências de viagens e turismo da cidade. Os resultados sugeriram a viabilidade da proposta de roteiro turístico e a preocupação de evidenciar a Reserva Indígena de Dourados no tocante a seus costumes, crenças e riquezas dentro da lógica indigenista/comunitária e não puramente economicista/capitalista do turismo tradicional.

Palavras-chaves: Turismo em terra indígena; Sustentabilidade; Reserva indígena de Dourados.

\section{INTRODUÇÃO}

Que é Ser? É ter um corpo, jeito, nome? Tenho os três, e Sou?

Homenagem a um artista desconhecido

O turismo em terra indígena ainda se mostra inviável em território brasileiro para a grande maioria dos grupos indígenas. Existem experiências inovadoras do ponto de vista da organização social, entretanto como dito inicialmente, pouco expressivas no cenário turístico brasileiro majoritariamente pautado no tempo "não indígena" de sua sociedade.

Entretanto já é uma realidade em países sul-americanos como a Bolívia, e o Equador que prioritariamente incentivam seus grupos a se organizarem no chamado turismo 


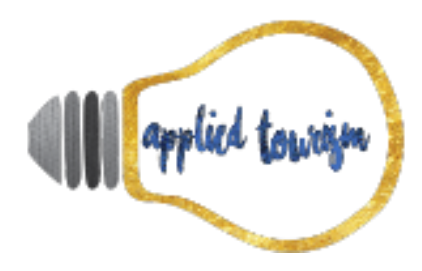

Volume 3, número 2, 2018, p. 36- 57

comunitário, o que permite uma transição mais silenciosa entre os dois tempos, o indígena e o não indígena, e seus encontros e desencontros.

Saliente-se, que no Brasil, a prática de turismo em terra indígena, vem se tornando uma realidade cada vez mais presente na vida dos grupos tradicionais como uma fonte de recurso econômico para sua sobrevivência. Frequentemente observa-se fluxo turístico em terras indígenas no Estado de Mato Grosso do Sul oriundos de agências de viagens que solicitam autorização de visitação para os órgãos de proteção de populações tradicionais, nesse caso a Fundação Nacional do Índio (FUNAI).

Os visitantes, quase sempre, vêm em busca do encontro com o outro que muitas vezes existe apenas no seu imaginário. Isso ocorre, tendo em vista, as terras indígenas hoje estarem próximas de grandes conglomerados urbanos, salvo exceções. O caso da Reserva Indígena de Dourados é emblemático quanto a essa condição.

Nesse contexto insere-se a Reserva Indígena de Dourados (RID), que vem promovendo incursões de turistas em suas terras e que vem potencialmente em busca do encontro com sua cultura, seu artesanatos o que desperta o olhar dos turistas. Destarte, para os grupos indígenas que vivem na RID, observou-se nesse fluxo turístico ainda que intermitente, um novo segmento de mercado turístico, que trabalha as potencialidades existentes em suas terras e consequentemente na práxis cotidiana.

Na RID, alguns recursos culturais se destacam e vão de ritos como a casa de reza onde se realizam cerimônias milenares dos grupos Guarani, as danças, exemplo: a dança do bate pau de guerra do grupo Terena, passando pelo artesanato dos três grupos que habitam a RID. Guardadas as devidas proporções, esses e tantos outros aspectos foram motivadores da proposta de elaboração de um roteiro turístico sustentável dentro da Reserva Indígena de Dourados, que garanta a autonomia da gestão e organização dos grupos ali residentes. Desse modo apresenta-se o objeto de estudo RID como sendo extensa área com alguns pontos específicos propostos para visitação: A casa de reza dos grupos Kaiowá, Guarani e 


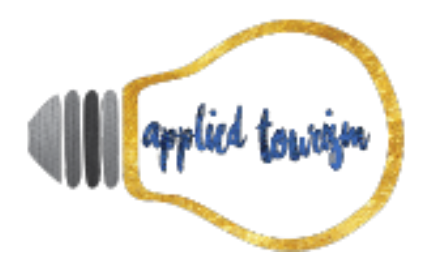

Volume 3, número 2, 2018, p. 36- 57

Terena, O Núcleo de Atividades Múltiplas (NAM) que fica a margem direita da rodovia estadual que liga o município de Dourados ao município vizinho de Itaporã e ainda a Vila Olímpica que foi construída para a realização das Olimpíadas Indígenas no ano de 2015, todos esses atrativos estão localizados no interior da RID.

A proposta inicial e o roteiro teórico metodológico primaram pela discussão em três dimensões da sustentabilidade: Social, Econômica e Ambiental, tendo em vista os três públicos que foram analisados (Acadêmicos da UEMS e UFGD, lideranças da reserva e também agentes de viagem locais) Sempre a luz de autores como Barreto (2007); Dias (2006) Panosso-Neto \& Gaeta (2010) e Urry (2001).

Nesse sentido Barreto discorre esse modelo de turismo como sendo aquele que:

[...] surge como uma alternativa por tratar-se de um turismo de minorias, cujos protagonistas, que seriam turistas não institucionalizadas, experimentais, experienciais e existenciais, são mais educados e respeitam o meio ambientes natural e cultural. Para que isso aconteça é fundamental que haja processo de planejamento participativo da comunidade que integre os recursos e aperfeiçoe de modo a dar continuidade neste segmento. (Barreto, 2007.p.84)

O turismo em terra indígena como dito anteriormente é tema controverso, para algumas pessoas, os indígenas são tidos como mercadoria a serviço do turismo. Esse é um dos aspectos negativos que precisam ser considerados frente à magnitude de uma proposta como essa. Entretanto pode vir a ser uma possibilidade de autonomia frente a assegurar formas de cultura e sobrevivência e também promover o acesso das pessoas envolvidas e imersas em uma sociedade de consumo.

Os resultados apresentados nesse trabalho refletem algumas atividades de pesquisa propostas como: acompanhamento de visitantes, entrevistas semiestruturadas as lideranças dos três grupos residentes na RID e ainda, visitas a quatro agências de viagens e turismo em Dourados/MS. A todos esses grupos foi aplicado questionário e os resultados finais apontam para a aceitação da criação de um roteiro turístico na RID mediante acompanhamento dos próprios indígenas e a construção de parâmetros de análise de uma possível intervenção não indígena no entorno e dentro do local de estudo. 


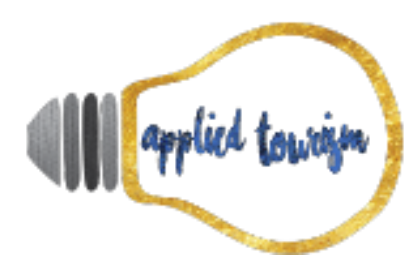

Volume 3, número 2, 2018, p. 36- 57

Esse artigo está dividido em seções. Os resultados que serão apresentados ao final dessa pesquisa e sustentam a base empírica de analise, tendo em vista que recorrentes vezes sugerem o cuidado ético e zelo pelos dados por parte do pesquisador responsável pela coleta e posterior analise.

\section{A IMPORTÂNCIA DO TURISMO NO MUNDO ATUAL}

Nos últimos anos do século XX, o mundo passou por um profundo processo de transformações em áreas como transportes, meio ambiente e expressões culturais, o que, de modo geral, caracteriza o fim do período moderno o inicia uma nova era. No entanto, no final do século XX, a importância da produção industrial para composição do Produto Interno Bruto - PIB, de diversas nações mostrou um declínio acentuado, frente ao avanço do terceiro setor, de serviços, tendência que se acentua neste início de século XXI.

A participação do turismo nesse novo cenário econômico tem aumentado sensivelmente, ao lado do comercio e do setor financeiro como aponta a Figura1.

Figura 1: Importância econômica do Turismo

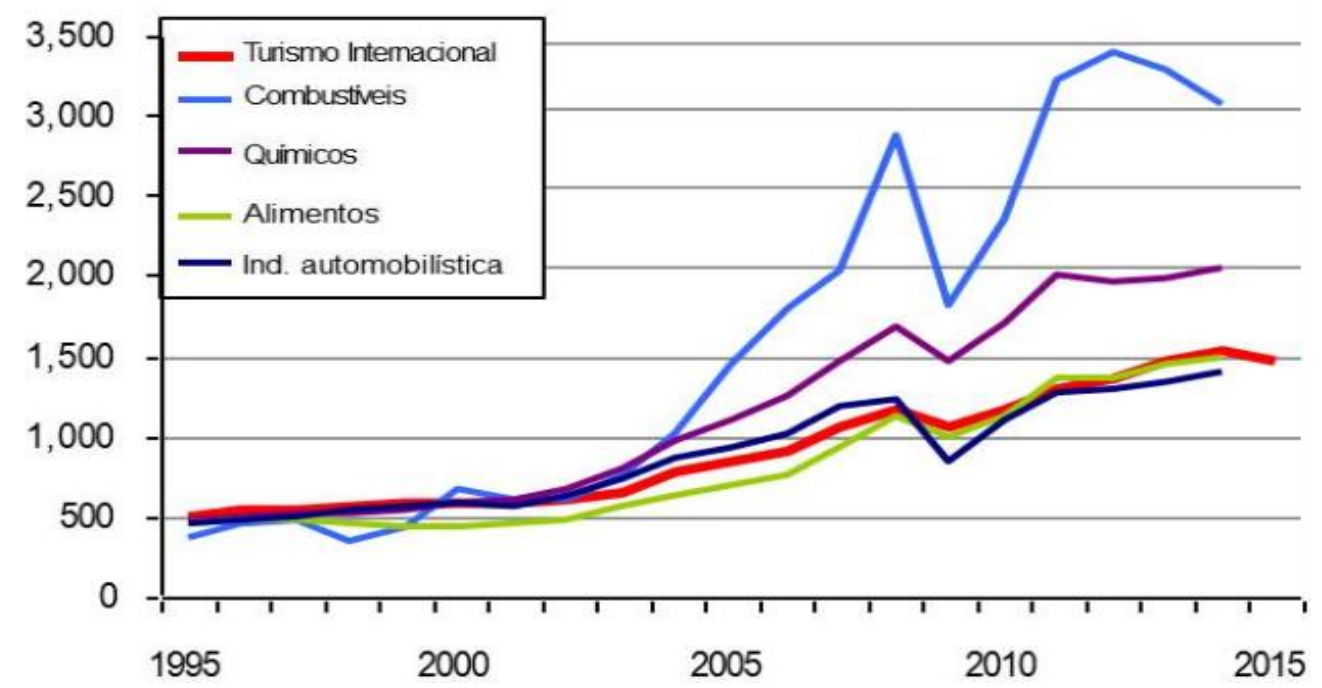

Fonte: Barômetro de viagens e turismo da OMT (2017). 


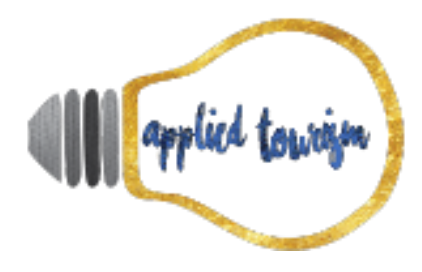

Volume 3, número 2, 2018, p. 36- 57

O turismo é o setor da economia que mais cresce, ainda não sendo capaz de superar commodities de exportação tradicionais como: alimentos, combustíveis e químicos, automóveis, sendo considerada a quarta principal atividade econômica mundial (OMT, 2017; DIAS, 2006).

Essa sequência pressupõe a conclusão que o turismo, enquanto setor de serviços movimenta uma série de fatores inter-relacionados, desde um ponto de barraca de vendas até grandes empresas. O Brasil, embora tenha recursos naturais e culturais extraordinários para o desenvolvimento da atividade turística, ainda está muito longe de auferir os dividendos que poderia obter com o turismo.

No movimento mundial de turistas, a participação do país continua muito pequena: somente $0.7 \%$ do total PIB. Se por um lado, os dados preocupam pela insignificância, por outro lado, revelam as possibilidades crescimento do setor em vista dos inúmeros recursos existentes, a maioria praticamente inexplorada ou mal explorados. Quanto ao turismo doméstico, de acordo com o IPEA (Instituto de Pesquisa Econômica Aplicada), anualmente, os brasileiros realizam algum tipo de viagem internamente representando 46 milhões de viagens internas.

Segundo proposição de Barreto (2007), o turismo, ao lado da Internet, é considerado, hoje, um dos principais mecanismos pelos quais ocorre a aproximação das diversas culturas mundiais e concretizam-se os intercâmbios virtuais, que crescem em um volume sem precedentes na história.

O crescimento do turismo e as projeções feitas pela OMT (2017) no relatório barômetro de viagens para os próximos anos acalentam o sonho, legitimo, de muitos lugares em obter vantagens econômicas desses fluxos. A OMT prevê um crescimento substancial do turismo nos próximos anos e estima que, nas viagens internacionais, estarão envolvidos 1,6 bilhão de chegadas até o ano de 2020, sem incluir o turismo doméstico que se consolida como o maior movimento de pessoas já ocorrido na história da humanidade. 


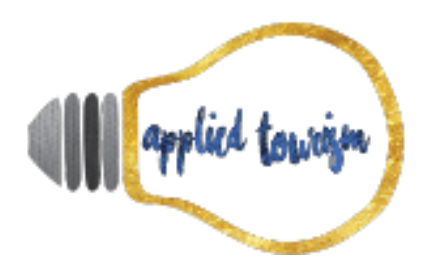

Volume 3, número 2, 2018, p. 36- 57

Por outro lado a preocupação está pautada também nas possibilidades de impactos irreversíveis em algumas sociedades gerando inúmeras consequências negativas, culturais e ambientais.

\section{O TURISMO EM TERRAS INDÍGENAS}

As estratégias de desenvolvimento da atividade turística em escala mundial podem ser observadas a partir da segmentação da atividade. Hoje se percebe entre outros segmentos, principalmente, tipologias e conceitos de base comunitária, culturais e de ecoturismo, nesse contexto se destaca o turismo em terras indígena como uma proposta de desenvolvimento local, de destaque de expressões culturais, entre outras possibilidades que esse segmento de turismo pode oferecer.

Nessa linha, a Organização Mundial do Turismo (OMT) em janeiro de 2004, da primeira conferência Mundial sobre as comunicações no turismo, realizada em Madri, a OMT lançou a campanha: Turismo e Riqueza, que pretende "criar uma consciência dos benefícios que esta atividade pode gerar para a vida, a cultura e a economia", além disso, tendia consolidar o turismo como "um direito humano básico e uma estilo de vida" entre os quais: para as exportações, geração de empregos, para as zonas rurais, investimentos em infraestruturas, Impostos e crescimento do PIB.

Deve-se atentar que a atividade turística da maneira convencional como ela se organiza quase nunca pode auxiliar nesse modelo de turismo segmentado em terra indígena. Nesse sentido uma forma de gestão não tradicional surge em oposição à força do capital financeiro de investimentos na atividade, dessa forma, as linhas de crédito designadas a agricultura familiar, e ou pequenos empreendimentos é uma alternativa a implantação de uma infraestrutura básica de apoio à atividade turística. 


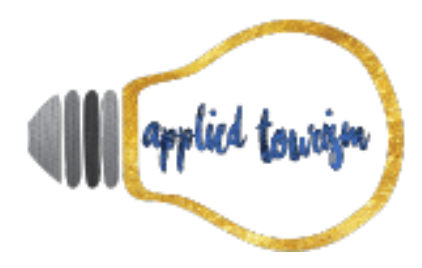

Volume 3, número 2, 2018, p. 36- 57

Surge assim, uma proposta de modelo de gestão puramente ligada ao autoctonismo, à autonomia e a um modelo de mercado sem entraves e com uma cadeia produtiva absolutamente ligada a centralidade do local onde as atividades ocorrem. Entretanto sabese que outras preocupações devem ser consideradas, entre elas, a ilegalidade desse modelo de turismo no Brasil. Muito se deve a resistência dos organismos gestores de grupos indígenas no país frente à possibilidade de aculturação quase sempre justificada em falas e documentos contrários, até o ano de 2015, ao turismo em terras indígenas.

A linha temporal sugere uma política que se iniciou com o Decreto $n^{\circ} 7.747 / 12$, instituindo a Política Nacional de Gestão Ambiental e Territorial de Terras Indígenas. Esta prevê no Eixo V, "g", total sustentação e regularização de iniciativas indígenas sustentáveis de etnoturismo e de ecoturismo respeitada à decisão da comunidade e a diversidade dos povos indígenas, promovendo-se, quando couber, estudos prévios, diagnósticos de impactos socioambientais e a capacitação das comunidades indígenas para a gestão dessas atividades.

No dia 11 de Junho de 2015 a FUNAI estabelece e publica a instrução normativa nº 3 que pretendia regularizar entre outros aspectos o conceito de etnoturismo e o segmento de ecoturismo em terra indígena. Desse modo os organismos indigenistas, pressionados por experiências turísticas voluntárias em terras indígenas no território brasileiro não puderam intervir de forma protecionista e foram de dentro para fora, ou seja, pelas populações envolvidas na atividade em suas terras movida a instituir a legalidade das atividades na forma das comunidades, ou seja, endogenamente e com características de gestão comunitária e autônoma.

Esses avanços foram previstos na construção dessa pesquisa e dessa forma, seguindo a proposição da instrução normativa $\mathrm{n}^{\circ} 3 \mathrm{em}$ seu artigo $1^{\circ}$ que cita: "Art. $1^{\circ}$ Ficam estabelecidas as normas para a visitação com fins turísticos em terras indígenas, de base comunitária e sustentável, nos segmentos de Etnoturismo e de Ecoturismo". Todo o procedimento de proposta de um roteiro e também da metodologia construtivista e participativa, sobretudo na iminência de manter a autonomia e o respeito à organização 


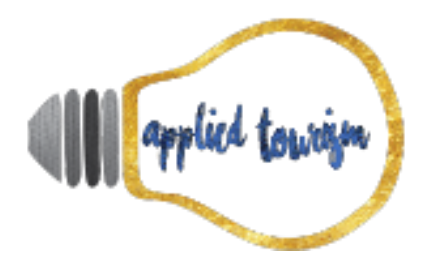

Volume 3, número 2, 2018, p. 36- 57

interna dos grupos envolvidos foi seguida, de certa maneira até mesmo o fato do pesquisador ser um membro do Grupo Guarani Kaiowá foi preponderante para obter os resultados que ora se discute.

Dessa forma segue o texto com uma caracterização do objeto de estudo, a RID que é estudada aqui como um recurso cultural importante na perspectiva do etnoturismo ou ainda do segmento de ecoturismo para o município de Dourados, amparado legalmente e na condição de protagonista na busca de investimentos de ordem pública e privada e também com vistas à gestão comunitária de suas crenças, artesanato e outras expressões culturais na terra indígena Bororó e Jaguapirú.

\section{Turismo na Reserva Indígena de Dourados - Mato Grosso do Sul.}

O Estado de Mato Grosso do Sul é considerado o segundo com maior número de população indígena do país, totalizando, segundo dados do IBGE/2010, 73.294 indígenas. Esta população reside em 75 aldeias, distribuída em 29 municípios, sendo das etnias Guarani e Kaiowá, Terena, Kadiwéu, Kinikinawa, Atikum, Guató e Ofaié.

O povo Guarani e Kaiowá corresponde a 43.396 indígenas (SESAI/MS - 2011), habitando a região chamada Cone Sul do estado, presente em 17 municípios e distribuído em 37 áreas indígenas, das quais oito são reservas. Nos últimos anos, várias áreas estão em processo de identificação, demarcação e homologação. O município de Dourados situa-se na parte Sul do Estado do Mato Grosso do Sul. A cidade possui 215.000 habitantes (IBGE, 2016) dos quais 10 \% são indígenas, principalmente de três grupos: Guarani Nhãndeva, Guarani Kaiowá e Terena.

A Reserva Indígena de Dourados é uma das terras reservadas para abrigar as populações indígenas dos três grupos ali presentes. O Município de Dourados possui em sua jurisdição, Terra Indígena Francisco Horta Barbosa, mais conhecida como Reserva Indígena de Dourados, está localizada ao norte da cidade de Dourados, a uma distância de apenas 5 km 


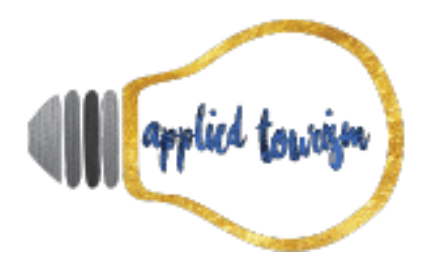

Volume 3, número 2, 2018, p. 36- 57

do centro da cidade, e ao sul da cidade de Itaporã, a uma distância de 15 km, com uma área total de 3.539 hectares e população de 13.313 indígenas (CENSO FUNASA-SESAI-2011).

Esses povos indígenas estão em uma área de disputa territorial, onde há expansão do cultivo não somente da cana de açúcar para abastecer a indústria do agro combustível, mas também da soja. Casos de óbitos decorrentes de desnutrição foram registrados nos últimos anos. A comunidade igualmente sofre com casos de homicídio, suicídios, alcoolismo e condições de trabalho precário e, em alguns casos, de trabalho forçado, com crianças e mulheres seriamente exposta a violação de seus direitos.

A situação fundiária é precária e há vários assentamentos indígenas à margem das estradas. A reserva tem a segunda maior população indígena do país. A Reserva Indígena de Dourados constitui o maior contingente de população indígena dentro de uma mesma reserva.

A área era conhecida como sendo tradicionalmente guarani, e no decorrer dos tempos sua população se distribuiu em dois subgrupos do povo guarani: Nhãndeva e Kaiowá, e o subgrupo terena: Aruak.

Os terenas possuem uma organização própria em que o contato com a sociedade não indígena é bem maior, assim perante os indigenistas se viu a oportunidade de se usar esse grupo para facilitar com o projeto de integração do guarani a sociedade nacional, podendo assim, facilitar a comunicação e futura conversão destes a cultura dominante, o que acontece até os dias atuais.

O objetivo de Implantação do turismo na Reserva Indígena de Dourados visa à visitação dentro de cada grupo familiar e mostrar valores culturais e tradições de cada etnia que ali reside, e também capacitar cada grupo familiar a receber os visitantes em sua comunidade. Essa troca de experiência deverá contemplar os visitantes e os visitados, viabilizando um fomento econômico e melhoria social diante dos fatores negativos da atualidade. 


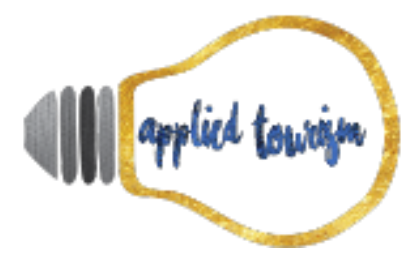

Volume 3, número 2, 2018, p. 36- 57

torne mais sustentável, dando uma contribuição mais positiva para o turismo sustentável" (Swarbrooke, 2000, p.49).

Neste contexto a comunidade indígena de Dourados, pode contribuir com o uso tradições e manifestações indígenas, que a aldeia que possui como potencial.

\section{MATERIAIS E MÉTODOS}

A seguir descrever-se as etapas que compõem essa pesquisa em campo na intensão de validar os aspectos já evidenciados nas bibliografias citadas. São três etapas estruturadas de acordo com as aspirações do pesquisador, sendo elas:

\section{$1^{\circ}$ Etapa - Revisão Bibliográfica e documental}

Essa etapa permitiu o levantamento das bibliografias que abordam temáticas tais como: Turismo em Terra Indígena, Turismo e Cultura, Turismo, Aspectos da Interculturalidade no Turismo, Turismo e Patrimônio, Turismo de Experiência. Dentre os autores citamos Urry (2001); Barreto (2007) Dias (2006) Panosso-Netto \& Gaeta (2010) entre outros que ajustam o modelo de analise proposto nesse trabalho, tendo em vista validar os aspectos de aplicação na Reserva Indígena de Dourados.

\section{$2^{\circ}$ Etapa - Pesquisa em campo.}

Durante a construção desse trabalho em três momentos os pesquisadores foram a campo. Durante a visita técnica realizada no dia 13 de Junho de 2017 que contou com presenças de acadêmicos do Curso de Turismo da Universidade Estadual de Mato Grosso do Sul e também com residentes em Nutrição, Enfermagem e Psicologia da Universidade Federal da Grande Dourados, lotados e trabalhando no programa de residência multiprofissional em saúde da UFGD. Também nos acompanharam os professores: Dr. Conrado Neves Sathler e a Profa. Graziela Britez Turdera. Os alunos ao final do roteiro proposto do Núcleo de Atividades Múltiplas (NAM) passando pela casa de reza do Seu Jorge, Vila Olímpica Indígena e Grupo Tradicional dos Terenas, responderam a um questionário contendo 10 questões que fazem parte da análise aqui contida. 


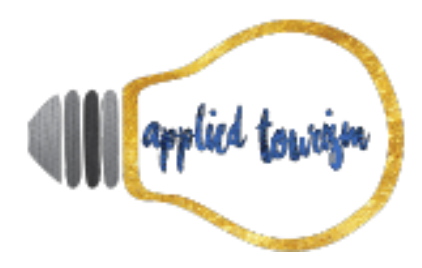

Volume 3, número 2, 2018, p. 36- 57

\section{$3^{\circ}$ Etapa - Analise e tabulaçãa dos dados.}

Essa compõe a última etapa desse trabalho baseia-se nas análises dos dados obtidos em campo, tabulados em um software do mercado, e também na ferramenta Excel e Word do Microsoft Windows 10. Foram tabulados em gráficos na forma de pizza e serão analisados nos resultados e discussões. Ao final, espera-se poder corroborar com as hipóteses dos autores supracitados ao longo da construção desse texto acadêmico.

\section{RESULTADOS E DISCUSSÕES}

O processo de análise baseou-se em três instrumentos de coletas de dados primários aplicados a grupos de interesse de forma aleatória e semiestruturada e ainda numa compilação sintética das respostas obtidas mediante algumas variações, tal como, questões fechadas em unanimidades, ou seja, com 100\% respondidas em sim e não, faremos uma interface das alternativas que foram propostas como uma frase para justificar a resposta ou ainda a resposta livre emitida pelo entrevistado. Iniciando as análises pelo fluxo de visitação identificado na Figura 2, as respostas se equivaleram entre o grupo, apontando um fluxo de 50\% de visitantes que já haviam estado em outro momento no interior da Reserva Indígena de Dourados por algum motivo que variou entre trabalho, visita a amigos e ou então projetos das universidades locais como apontado na Figura 3 a seguir:

Figura 2 - Fluxo de visitação Figura 3 - Motivos da visita anterior
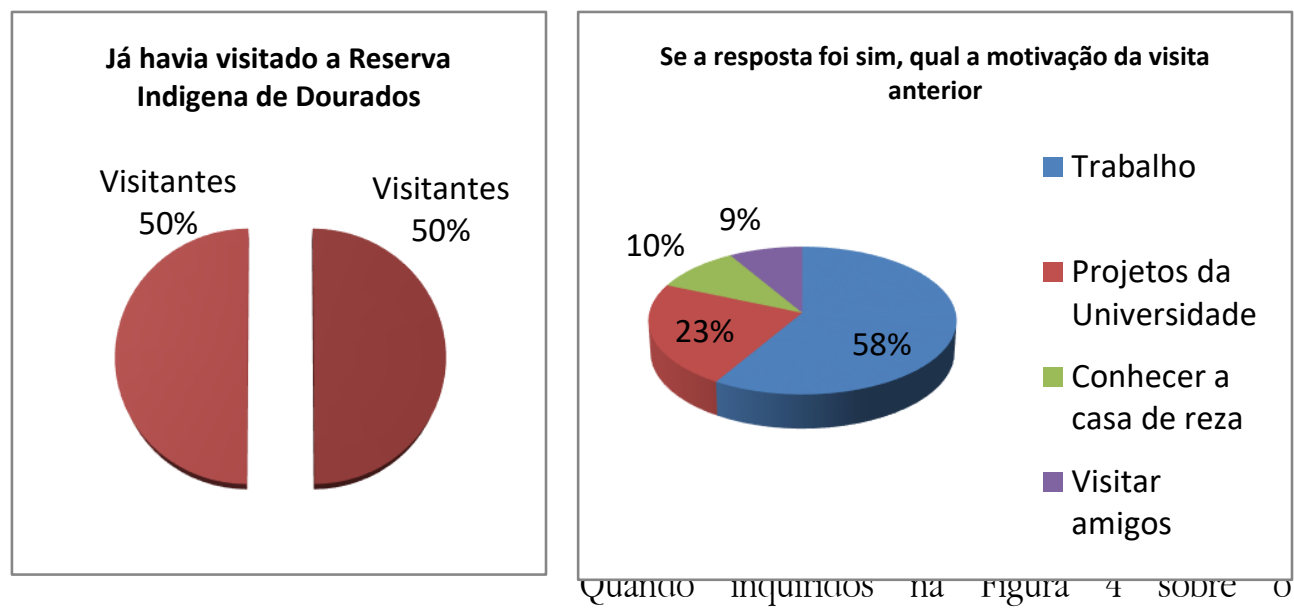

conhecimento do conceito de turismo em terra indígena, também houve certa distorção nos dados. Ou seja, a metade dos entrevistados alegou conhecer o conceito, o que causa 


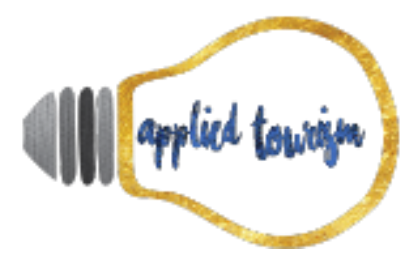

Volume 3, número 2, 2018, p. 36- 57

surpresa, tendo em vista, o conceito de turismo em terra indígena ainda ser bem inexpressivo, em comparação com Ecoturismo e Turismo de Aventura, por exemplo.

Figura 4 - Conhece o conceito de terra indígena

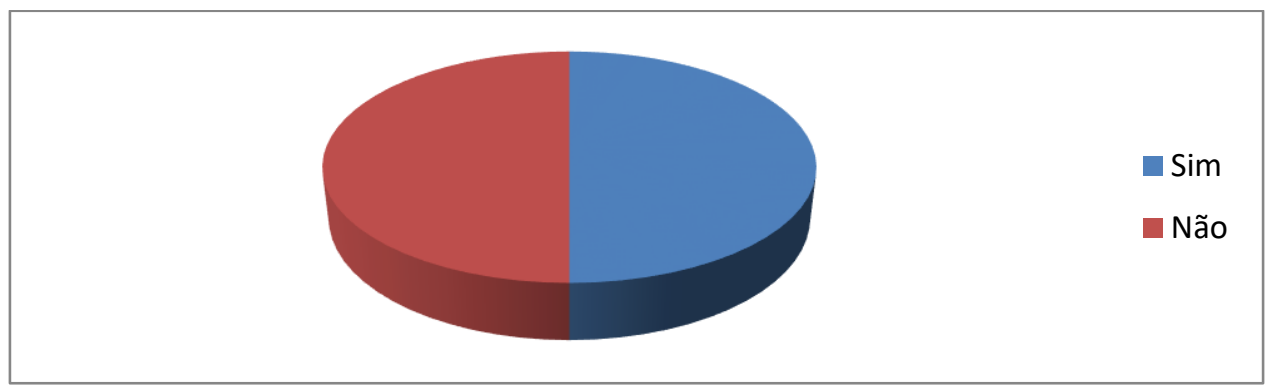

Fonte: elaborado pelos autores (2017).

Dessa forma na figura 5 se inquiriu sobre a visibilidade dos aspectos do cotidiano que foram apresentados e se na iminência de haver um roteiro estabelecido de turismo em terra indígena, se o entrevistado traria algum par seu para visitar a aldeia, a resposta foi sim e trouxe o primeiro caso de unanimidade na primeira resposta, decidimos então inquirir o entrevistado sobre interfaces de sua resposta como justificativa. Os dados apontam justificativas que vão desde a existência da cultura com outro, de novos aprendizados, e também experiências distintas do cotidiano não indígena.

Figura 5 - Interfaces com a palavra cultura

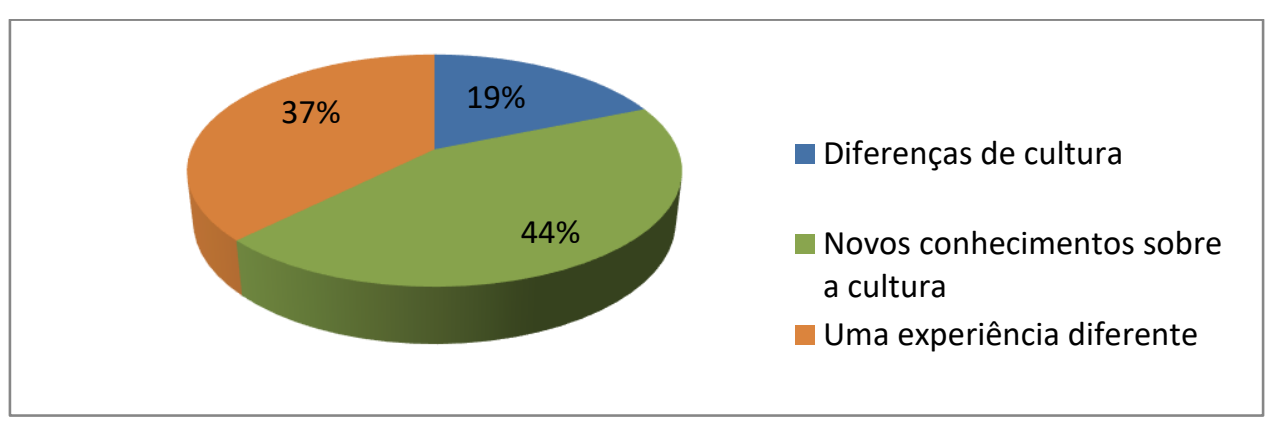

Fonte: elaborado pelos autores (2017).

Quando entrevistados com a questão tabulada na Figura 6 se achava importante o turismo em terra indígena no interior da Reserva Indígena de Dourados novamente houve unanimidade do sim, entretanto as interfaces novamente foram identificadas como sendo de interesse dos entrevistados, tais como: Exotismo, Preservação Cultural, Saberes, Artesanato, Danças, etc.

Figura 6: Importância do Turismo na Reserva Indígena de Dourados 
Volume 3, número 2, 2018, p. 36- 57

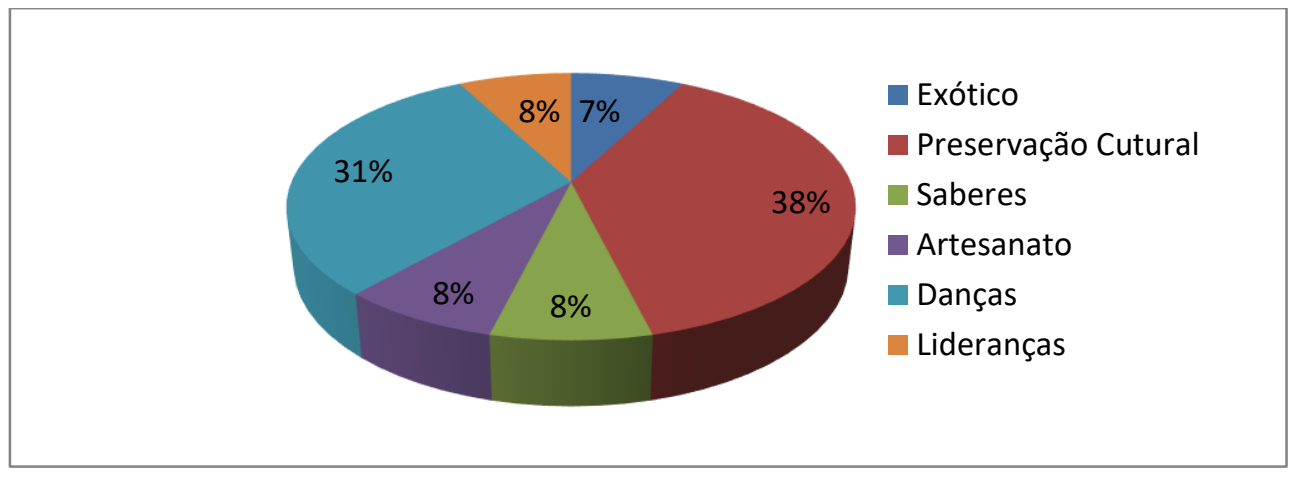

Fonte: elaborado pelos autores (2017).

Questionados se havia potencial na opinião do entrevistado, na Reserva Indígena de Dourados, a imensa maioria defendeu a possibilidade de existência de um roteiro para visitação turística no interior da Reserva, apenas dois entrevistados, ou seja, a representação de 13\% dos entrevistados não quis opinar sobre essa possibilidade.

Quanto às questões de trato sustentável a maioria indicou o turismo em terra indígena como opção de desenvolvimento da comunidade local e ainda citaram alguns aspectos positivos dessa atividade, caso seja implementada, tais como: Fortalecimento da cultura, envolvimento da comunidade local, valorização da identidade, renda e qualidade de vida, entretanto, um dos entrevistados apontou sua preocupação com a má organização do turismo em outros destinos, o que trouxe inúmeros prejuízos às comunidades.

Na Figura 7 a questão estava relacionada com as experiências dos questionados frente à realidade do município de Dourados, sua população indígena e o tratamento dispensado a ela por parte de integrantes dessa realidade. As contribuições podem ser observadas na figura abaixo e apontam inclusive para uma palavra que muito nos chama a atenção que é o preconceito contra esses grupos lançados quase que diariamente por parte da sociedade douradense

Figura 7 - Como o turismo sustentável pode contribuir na relação indígenas x não indígenas 
Volume 3, número 2, 2018, p. 36- 57

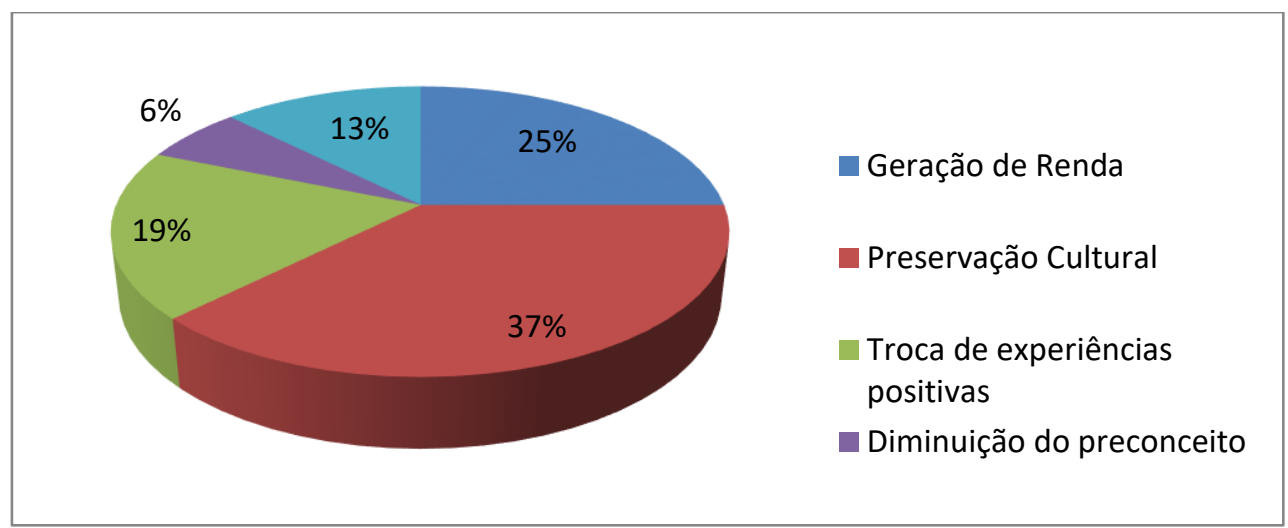

Fonte: elaborado pelos autores (2017).

Ainda na questão da Figura 7 observaram-se outras contribuições por parte dos entrevistados, tendo em vista, geração de renda, preservação da cultura da comunidade e de suas tradições. Esses encontros e desencontros são de conhecimento público e notório, cantados em versos e poemas. O turismo pode sim amenizar essa discrepância se for organizado pela comunidade no sistema de base comunitária, por exemplo, que é uma das garantias da autonomia comunitária frente ao modelo hegemônico do turismo convencional.

A Figura 8 e última versa sobre a importância das representações culturais no interior da Reserva Indígena de Dourados. A resposta sim foi unanime e as interfaces apontadas para essa importância e vai desde riqueza das representações, conhecimento, manutenção da cultura, fortalecimento e divulgação cultural dos três grupos que compõem a Reserva indígena de Dourados. O fator cultural, aliás, está presente invariavelmente em todas as questões como um elemento provocativo por parte dos autores, tendo em vista a exoticidade quase sempre povoar o imaginário dos sujeitos antes dos encontros. Eles aconteceram e deixaram profundas marcas em todos

Figura 8 - Importância da representação cultural 


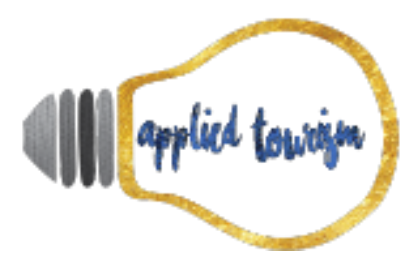

Volume 3, número 2, 2018, p. 36- 57

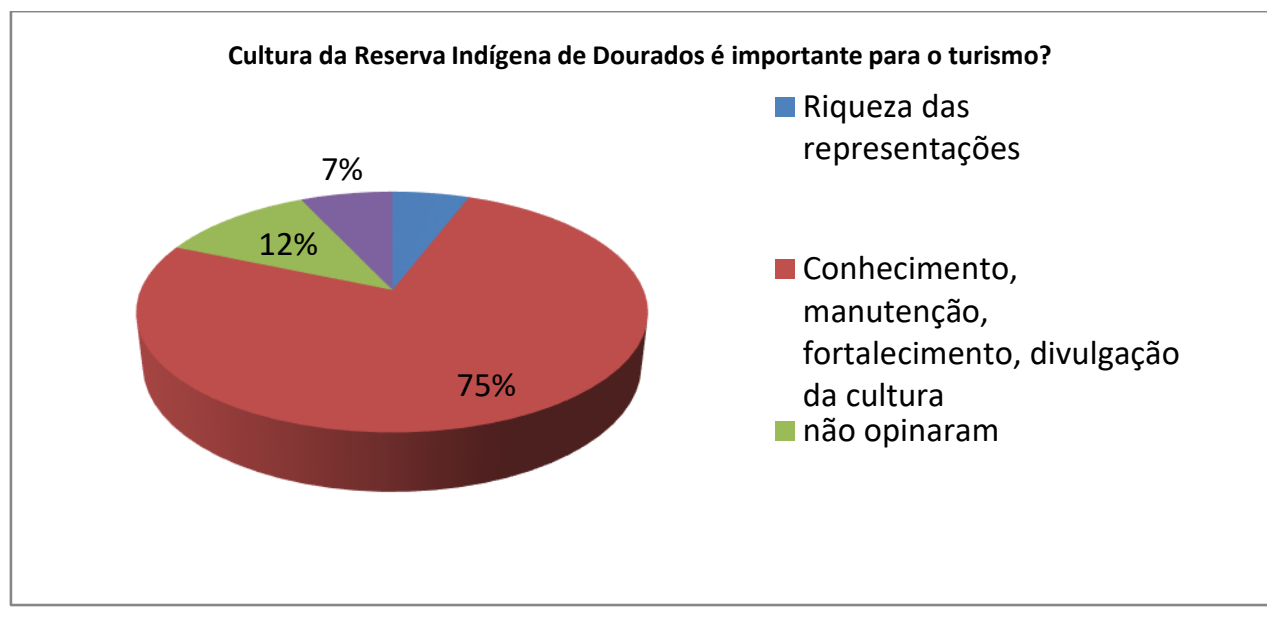

Fonte: elaborado pelos autores (2017).

Ao final a aplicação dos questionários entre os acadêmicos e professores convidados atendeu a um dos objetivos e a metodologia estabelecida previamente. Foi satisfatório o resultado e os dados apontam para corroborar as teses dos autores citados na contextualização teórica desse trabalho. Dessa forma ficou provado, que o turismo em terra indígena ainda que não gere grandes impactos de crescimento e desenvolvimento econômico na Reserva Indígena de Dourados, ao menos, na opinião dos entrevistados e dos autores citados, ele colaborará na manutenção de aspectos de tradição e interesse social coletivo, dentro e fora da Reserva.

Em um segundo momento a entrevista foi encaminhada com as lideranças dos três grupos indígenas que habitam a Reserva Indígena de Dourados e continha questões que inquirem desde o nível de conhecimento da atividade turística de experiência, passando pela crença no potencial para o turismo ali existente e também visando resgatar possíveis fluxos turísticos de épocas passadas na Reserva.

Questão no 1 - O que o $\operatorname{Sr}$ (a) entende por turismo de experiência? "Uma vivência única" diz o Cacique Kaiowá (Jorge da Silva). "É uma troca de
vivência e experiência nova." Cacique terena (Renato Jorge). "Implantar e
esperar o resultado" secretária de liderança Indígena (Magna Freitas
Correia). "Tenho certeza que, o turismo de experiência e uma forma de
organizar o valor cultural de cada povo existente aqui" Coordenador de
cultura (Édio Felipe Valério). "Uma ação concreta que visa um
empreendimento de uma atividade turística num local" professor (FUNAI)
(João Machado). "Acho que é o ato de mostrar nossas potencialidades
culturais, e difundir nossa cultura." Advogado, Coordenador Regional do 


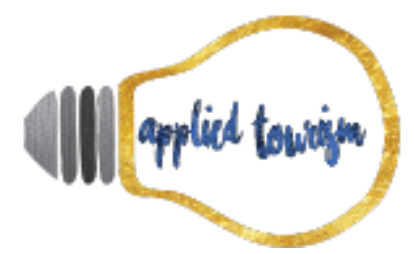

Volume 3, número 2, 2018, p. 36- 57

CINEP/ODIN (Observatório de Direitos Indígenas- Regional do Centro Oeste.) (Wilson Matos da Silva). Não respondeu o enfermeiro Kaiowá (Silvio Ortiz).

Questão n 2 - Você considera esse "modelo" turismo de experiência importante?

"Muito importante, pois é uma das fontes de geração de renda." advogado (Wilson Matos da Silva,). "Sim porque é um diagnóstico de uma atividade a desenvolver" professor (João Machado). "Fica muito bom esse trabalho porque é um trabalho de transparência para nossa comunidade." Coordenador de cultura (Édio Felipe Valério). Não respondeu o enfermeiro Kaiowá (Silvio Ortiz). "Sim vamos mostrar e aprender, o que temos de bom e bonito na aldeia." Secretária de liderança Indígena (Magna Freitas Correia). "Sim! Importante para a comunidade em geral" Cacique Terena (Renato Jorge). "Sim" Cacique Kaiowá (Jorge da Silva).

Questão no 3 - Existe alguma política de turismo dentro da Reserva Indígena de Dourados?

"Turismo existe, mas sem definição" Cacique Kaiowá (Jorge da Silva). "Não existe" Cacique Terena (Renato Jorge). "Não" secretária (Magna Freitas Correia). "Não de forma formal" enfermeiro (Silvio Ortiz). "Temos alguns projetos de viabilizar, o turismo dentro da Reserva, mas independentemente da política pública" coordenador de cultura (Édio Felipe Valério). "Não" professor (João Machado). "Ainda não, houve uma pequena experiência, mas, não vingou por ser imposta por terceiros, estranho ao convívio da comunidade" advogado (Wilson Matos da Silva).

Questão no 4 - Há ou houve movimento de turistas na aldeia nos últimos anos?

"Então, alguns anos atrás, o Alphonsus hotel levava grupos de turistas até a aldeia, mas, não havia um roteiro que fosse trabalhado junto com a comunidade" advogado (Wilson Matos da Silva). "Sim, mas em movimentos esporádicos" professor (João Machado). "Foi formalizado entre a vinda de turismo entre os hotéis de Dourados, mas faltou organização" coordenador de cultura (Édio Felipe Valério). "Sim" enfermeiro (Silvio Ortiz). "Sim" secretária de liderança Indígena (Magna Freitas Correia). "Sim! Vários" Cacique Terena (Renato Jorge). "Sim!" Cacique Kaiowá (Jorge da Silva).

Questão n ${ }^{0} 5$ - Você acredita que a Reserva Indígena Jaguapirú tenha potencial para o turismo de experiência?

"Sim, porque é uma troca de experiência" Cacique Kaiowá (Jorge da Silva). "Sim! Visa economia local" Cacique Terena (Renato Jorge). "Sim! Por várias razões, a aldeia tem seu potencial riquíssimo para ser valorizada" secretária de liderança Indígena (Magna Freitas Correia). "Jaguapirú e Bororó, tem potencial sim" enfermeiro (Silvio Ortiz). "Sim: devemos pontua lizar os pontos principais, para que a visitas feitas realiza suas curiosidades" coordenador de cultura (Édio Felipe Valério). "Sim! Porque a própria cidade não oferece opções de visitas" professor (João Machado). "Sim, pois a troca de experiência desde o "descobrimento" houve uma gama de aprendizado de ambos os lados exatamente pela troca de experiência." Advogado (Wilson Matos da Silva).

Questão no 6 - Quem organiza a atividade econômica do turismo dentro da Reserva Indígena Jaguapirú? 


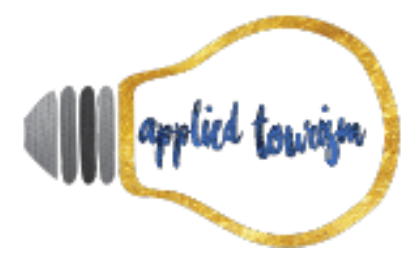

Volume 3, número 2, 2018, p. 36- 57

"Ainda não temos, acredito que o setor representativo da cultura, do conselho da aldeia e da CEAIND/Prefeitura possa cooperar na implementação de um roteiro." Advogado (Wilson Matos da Silva). "Os Nhânderu, nas casas de rezas" professor (João Machado). "Eu que faço parte entre um deles na cultura, guando vem o turismo na reserva. agente encaminha para o grupo étnico, que agente tem contato." coordenador de cultura (Édio Felipe Valério). "A organização é de forma independente de forma isolada" enfermeiro (Silvio Ortiz). "Não respondeu" secretária de liderança Indígena (Magna Freitas Correia). "Não temos" Cacique Terena (Renato Jorge). "Não sei" Cacique Kaiowá (Jorge da Silva).

Questão n ${ }^{0} 7$ - Um bacharel em turismo da própria Reserva Indígena de Dourados seria importante na organização do turismo de experiência internamente?

"Sim! Por ter diálogo e conhecimento do local" Cacique Kaiowá (Jorge da Silva). "Com certeza temos que ter" Cacique terena (Renato Jorge). "Sim! Por conhecer os pontos, e uma boa comunicação com a comunidade" secretária de liderança Indígena (Magna Freitas Correia). "Não há necessidade necessariamente bacharel, mas as comunidades com incentivo pode oferecer grande potencial" enfermeiro (Silvio Ortiz). "Muito importante, porque isso fara a organização de lugares para a visita aqui na aldeia" coordenador de cultura (Édio Felipe Valério). "Sim! Porque, teria uma formação especifica" professor (João Machado). "Com certeza, pois a língua materna é muito importante para esclarecer o empreendimento e o conhecimento e a vivencia ajuda na motivação dos participantes" Advogado (Wilson Matos da Silva).

Questão $n^{0} 8$ - O Sr (a) acha que os grupos Kaiowá Guarani e Terena participariam da experiência do turismo na Reserva Indígena de Dourados?

"Acho que não todos por que a pessoa que estava á frente não era habilitada e era estranha ao convívio da comunidade, mas, penso que com uma pessoa que seja habilitada e membro da comunidade a adesão seria total" Advogado (Wilson Matos da Silva). "Não muito pouco" professor (João Machado). "O grupo sempre esteve presente, nas apresentações para os visitantes, tenho certeza que estarão participando" coordenador de cultura (Édio Felipe Valério). "Com certeza, na verdade já existe esta atividade, porem falta apoio é incentivo" enfermeiro (Silvio Ortiz). "Com muito prazer e interesse" secretária de liderança Indígena (Magna Freitas Correia). "Sim!" Cacique Terena (Renato Jorge). "Sim!" Cacique Kaiowá (Jorge da Silva).

Questão n9 - Como os grupos Kaiowá, Guarani e Terena seriam beneficiados socialmente com Implantação do turismo na Reserva Indígena de Dourados?

"Sim" Cacique Kaiowá (Jorge da Silva). "Sim" Cacique Terena (Renato Jorge). "Com um avanço muito grande de alta valorização em seus conhecimentos" secretária de liderança Indígena (Magna Freitas Correia). "Além de outros benefícios poderá resgatar auto/estima" enfermeiro (Silvio Ortiz). "Tenho certeza podemos organizar um pacote de valor, para o grupo de danças, e os artesões com suas vendas" coordenador de cultura (Édio Felipe Valério). "Através de renda e venda de artesanatos e divulgação de culturas dos povos" professor (João Machado). "Além da troca de experiência, o que por si só é muito salutar, haveria a possibilidade da criação de uma fonte de renda aos indígenas." Advogado (Wilson Matos da Silva).

Questão n ${ }^{0} 10$ - O Sr (a) é favorável ao turismo na Reserva Indígena de Dourados? 


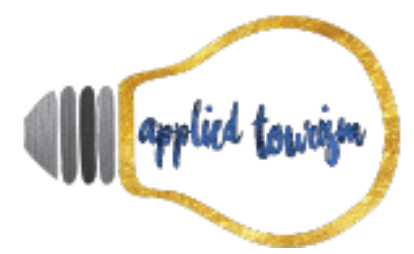

Volume 3, número 2, 2018, p. 36- 57

\begin{abstract}
"Sou favorável, por que é um meio de difusão de nossas culturas e tradições no meio "civilizado." E ainda é possibilidade de troca de experiência com pessoas de outros países." Advogado (Wilson Matos da Silva). "Sim!" professor (João Machado). "Com certeza, pode contar conosco, seja bem vindo o nosso projeto" coordenador de cultura (Édio Felipe Valério). "Sim, tem muito a divulgar coisas boas, e não só as negativas" enfermeiro (Silvio Ortiz). "' Sim, a minha comunidade tem muito para mostrar e um valor riquíssimo e pouco divulgado, pelo outro lado, lado branco da aldeia" Paz" secretária de liderança Indígena (Magna Freitas Correia). "Sim!" Cacique Terena (Renato Jorge). "Sim”! "Cacique Kaiowá (Jorge da Silva)".
\end{abstract}

Outro grupo que foi inquirido durante a construção desse trabalho foram os agentes de viagens e turismo. Vale ressaltar que ainda que haja uma limitação das agências do município de Dourados, pois essas atendem apenas o mercado de turista emissivo, saber o que esses agentes pensam sobre a proposta do artigo, nos ajudou a perceber entre outros aspectos, certo receio por parte desse componente da oferta turística, tendo em vista, ouvirmos afirmação de que o interior da aldeia é perigoso, entretanto quando questionado sobre o real conhecimento da Reserva Indígena de Dourados, poucos sabiam onde ficavam os atrativos e onde seria mantida a estrutura das visitações. Segue análise sobre esse grupo entrevistado

Questão $n^{\circ} 1$ - Você considera o turismo em Terra Indígena importante?

AGENTE: Zann Turismo: "Importantíssimo para o desenvolvimento do Turismo Local, porque tem tudo haver com nossas raízes culturais e nossa vocação de agronegócio. Agora implementar políticas para unir essas potencialidades ai que tá o gargalo".

DM TUR AGENCIA - R: "Não".

AGENCIA Ana Paula Turismo- R: "Sim, mas no nosso caso fica fora da rotina, mas citou um professor que já trabalhou nessa questão".

Questão n 2 - Existe alguma política pública de turismo, para que as agências de viagens da cidade de Dourados possa ter um trabalho em conjunto as comunidades dentro da Reserva Indígena de Dourados?

AGENCIA: Zann Turismo R: "Que saiba apenas a Passeio Turismo e um projeto do Receptivo Dourados".

DM TUR AGENCIA- R: "Não existe nenhuma politico. Única agencia que trabalha com receptivo na cidade e a Passeio Turismo".

AGENCIA Ana Paula Turismo: R "Apenas a Passeio Turismo e um projeto do Receptivo Dourados".

Questão n 3 - Você acredita que a Aldeia Indígena de Dourados tem o potencial para o turismo?

AGENCIA: Zann Turismo R: "Acho sim, mas necessita de um projeto amplo e de parcerias". 


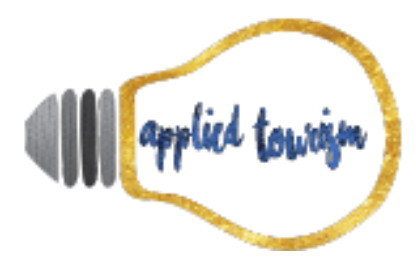

Volume 3, número 2, 2018, p. 36- 57

DM TUR AGENCIA- R: "Sim, porém cabe saber se a agencia que atua nessa segmentação tem interesse em trabalhar com esse tipo de turismo".

AGENCIA Ana Paula Turismo- R: "Sim, a preocupação é ter a contra partida da própria comunidade".

Questão 4 - Existe algum setor responsável pelas ações de Turismo na Reserva Indígena de Dourados, quando sua agência precisar levar turistas com segurança dentro da Aldeia?

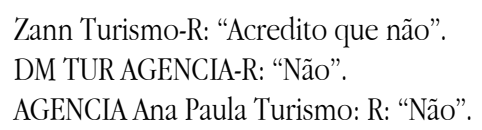

Questão n ${ }^{\circ}$ 5- Existe alguma pessoa qualificada que você conhece na área de turismo em terra indígena, que possa intermediar trabalho em conjunto as agências?

AGENCIA- Zann Turismo R: "Não conheço, o Prof. Munier Abrão pode te ajudar". DM TUR AGENCIA- R: "Não conheço".

AGENCIA Ana Paula Turismo: R: "lembro-me do professor Djanires Netto" Questão n 6 - Tendo essa pessoa qualificada, a se comprometer a capacitar as pessoas da comunidade para recepcionar os visitantes, pra você é interessante?

Zann Turismo - R: "Sim, sempre importante".

DM TUR AGENCIA- R: "Se houvesse uma pessoa qualificada sem duvida seria interessante o investimento em visitar a aldeia indígena".

AGENCIA Ana Paula Turismo: R: "Sim muito importante".

Questão n ${ }^{\circ}$ 7-Existindo roteiros turísticos com os pontos específicos no interior da aldeia, para recepcionar os turistas, para a sua agência é importante?

\footnotetext{
Zann Turismo R: "Sim".

DM TUR AGENCIA- R: "Para a agência no momento não seria importante, pois não atuamos com o receptivo, porem acreditamos que para 0 município seria algo importante, pois poderíamos trabalhar de certa forma o turismo nessa segmentação".

AGENCIA Ana Paula Turismo: R: "Sim, é um ponto positivo".
}

É salutar apontar para alternativas econômicas e justificar que proposições de turismo em terra indígena, hoje legais, podem gerar efeitos econômicos importantes para os atores envolvidos, tendo em vista, o comércio de artesanato, as expressões culturais, os ritos, entretanto sempre de maneira autônoma e não intervencionista e ainda menos com a imposição do mercado do turismo convencional, ou seja, os recursos gerados no interior das comunidades devem ser apropriados pela própria comunidade.

Dessa maneira a proposta é vista como economicamente viável e sugere a existência de fluxos turísticos e de uma alternativa econômica aos grupos envolvidos. Observa-se ainda por força de norma dos organismos indigenistas envolvidos que se abre possibilidade de 


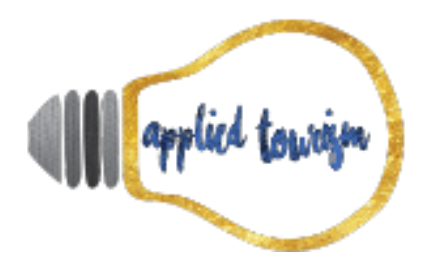

Volume 3, número 2, 2018, p. 36- 57

investimentos por parte de setores públicos e privados e ainda parcerias, o que de certa maneira poderia estar atrelado a incentivos fiscais de setores como agricultura, pecuária e indústria no Estado do Mato Grosso do Sul, tendo em vista serem estes expoentes na economia local.

As alternativas igualmente atrelam-se a incorporação de novas possibilidades de desenvolvimento do município de Dourados e sua importância no cenário econômico do centro oeste do país, tido como importante polo tecnológico com nível de relações internacionais desempenhado por algumas das gigantes do agronegócio. Todos esses fatores integrados podem auxiliar e facilitar o aporte de recursos para investimento privado na RID.

Outro aspecto importante é que o município juntamente com a capital do estado, Campo Grande é trânsito obrigatório dos fluxos turísticos de turistas que se deslocam das regiões sul, sudeste e de outras regiões ao destino turístico de Bonito, considerado a capital mundial do ecoturismo, dessa forma, uma gestão integrada de informações poderia gerar ainda mais atratividade ao destino citado, tendo em vista, ressalte-se ecoturismo estar associado em última análise ao envolvimento de populações tradicionais.

Sendo assim, analisou-se durante todo o processo de construção dessa pesquisa em nível de prospecção de mercado de alternativas para a comunidade estudada. Saliente-se que as riquezas culturais e os saberes identificados remetem a ancestralidade e necessitam de preservação e valorização, aspectos que dificilmente resistem no modelo atual de desenvolvimento, nesse sentido identifica-los não é suficiente, cabe ao capital de alguma forma incentivar a coexistência de outras formas econômicas ainda que em ritmos, tempos e interesses distintos.

\section{CONSIDERAÇÕES FINAIS}

Observou-se que há entre os grupos pesquisados, boas expectativas sobre o turismo em terra indígena. Apesar de recente mercadologicamente falando esse segmento de turismo 


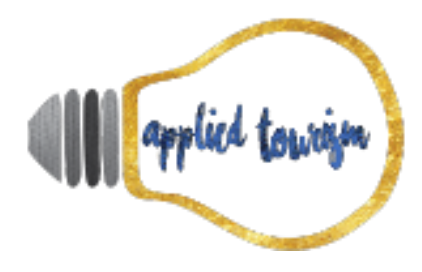

Volume 3, número 2, 2018, p. 36- 57

tende a sofrer algumas alterações de ordem legal iniciadas com a instrução normativa n 3 e a Política Nacional de Gestão Ambiental de Terras Indígenas

Por outro lado, evidenciou-se que tanto a preservação, quanto a conservação da cultura local, ou seja, no interior da Reserva Indígena de Dourados, é uma preocupação dos entrevistados.

Outro aspecto é que recorridas vezes a preocupação com o processo de implantação do suposto roteiro, é adjetivado com o ideário do planejamento que leve em consideração a cultura dos grupos envolvidos, o que de certa forma demonstra a preocupação com a manutenção da tradição encontrada no interior da reserva.

Outro aspecto de importância está atrelado ao modelo de gestão do hipotético atrativo. Deve ser autônomo na visão dos pesquisadores e de entrevistados. Não deve em hipótese alguma corroborar a visão puramente econômica do turismo convencional e assim, precisa evidenciar os grupos envolvidos e suas tradições ancestrais, seu cotidiano, seu lugar, isso tudo atrelado à possibilidade de um desenvolvimento na ordem local.

Entende-se a proposta como viável. Propõe-se, no entanto, um aprofundamento do objeto em outros trabalhos e experiência de mercado já implantadas indígenas, ou não, na iminência de corroborarmos a ideia ora apresentada.

Nesse interim ainda a proposição desse artigo sugere a abertura da RID ao mercado do turismo em terra indígena, com gestão de base comunitária, não convencional, dessa forma, representando o alvorecer de uma autonomia econômica e alternativa a RID, As dificuldades no lugar persistem, porém nada que desanime os incentivadores de um modelo não protecionista de turismo em terra indígena no local. Aguardemos e esperemos por novos ventos ancestrais. 


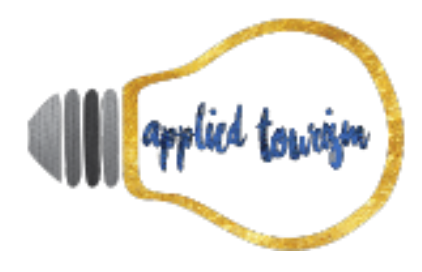

Volume 3, número 2, 2018, p. 36- 57

\section{REFERÊNCIAS}

Barretto, M. (2007). Cultura e turismo. Papirus Editora.

Brasil. Decreto no 7.747, de 5 de junho de 2012 (2012). Institui a Política Nacional de Gestão Territorial e Ambiental de Terras Indigenas - PNGATI, e dá outras providências.

Brasil, Ministério da Saúde (2002). Política Nacional de Atenção à Saúde dos Povos Indígenas.

Brasil, Ministério da Justiça Fundação Nacional do Índio (2015). Instrução Normativa no 3, de 11 de Junho de 2015. Estabelece normas e diretrizes relativas às atividades de visitação para fins turísticos em terras indígenas.

Dias, R. (2006). Turismo e patrimônio cultural: recursos que acompanbam o crescimento das cidades. Saraiva.

OMT. (2017). Relatório Barômetro de Viagens e Turismo. Espanha, ES. 2017.

Panosso-Netto, A; Gaeta. C. (2010). Turismo de Experiência. Senac.

Swarbrooke, J. (2000). Turismo sustentável: turismo cultural, ecoturismo e ética. Aleph.

Urry, J. (2001). O olhar do turista. Studio Nobel. 